Article

\title{
End-User Attitudes towards Location-Based Services and Future Mobile Wireless Devices: The Students' Perspective
}

\section{Elena-Simona Lohan ${ }^{1}$, Alexandru Rusu-Casandra ${ }^{2}$, Oana Cramariuc ${ }^{3 *}$, Ion Marghescu ${ }^{2}$ and Bogdan Cramariuc ${ }^{4}$}

1 Tampere University of Technology, Department of Communications Engineering, Tampere, PO Box 692 FIN-33101, Finland; E-Mail: elena-simona.lohan@tut.fi

2 Faculty of Electronics, Telecommunications and Information Technology, University Politehnica of Bucharest, Bucharest 060042, Romania; E-Mails: rusu.alex@yahoo.com(A.R.C.); marion@comm.pub.ro(I.M.)

3 Tampere University of Technology, Department of Physics, Tampere PO Box 692 FIN-33101, Finland

4 IT Center for Science and Technology (CITST), Bucharest 060042, Romania; E-Mail: bogdan.cramariuc@citst.ro

* Author to whom correspondence should be addressed. E-Mail: oana.cramariuc@tut.fi; Tel.: +358-401981183; Fax: +358-331153015.

Received: 6 May 2011; in revised form: 24 June 2011 / Accepted: 28 June 2011 / Published: 18 July 2011

\begin{abstract}
Nowadays, location-enabled mobile phones are becoming more and more widespread. Various players in the mobile business forecast that, in the future, a significant part of total wireless revenue will come from Location-Based Services (LBS). An LBS system extracts information about the user's geographical location and provides services based on the positioning information. A successful LBS service should create value for the end-user, by satisfying some of the users' needs or wants, and at the same time preserving the key factors of the mobile wireless device, such as low costs, low battery consumption, and small size. From many users' perspectives, location services and mobile location capabilities are still rather poorly known and poorly understood. The aim of this research is to investigate users' views on the LBS, their requirements in terms of mobile device characteristics, their concerns in terms of privacy and usability, and their opinion on LBS applications that might increase the social wellbeing in the future wireless world. Our research is based on two surveys performed among 105 students (average student age: 24 years) from two European technical universities. The survey questions were intended to
\end{abstract}


solicit the youngsters' views on present and future technological trends and on their perceived needs and wishes regarding Location-Based Services, with the aim of obtaining a better understanding of designer constraints when building a location receiver and generating new ideas related to potential future killer LBS applications.

Keywords: cellular location; Global Navigation Satellite Systems (GNSS); Location-Based Services (LBS); LBS-enables social wellbeing; LBS features; privacy concerns; user interactivity assent; user survey; Tampere University of Technology (TUT); University Politehnica of Bucharest (UPB); WLAN location

\section{Background}

User needs and wishes are the most important factors to be taken into account when designing new services on mobile devices. Location-Based Services (LBS) are defined in [1] as commercial locationsensitive applications and services that utilize geographical positioning information of a mobile device's location to provide value-added services to users. Another definition given by [2] considers LBS as a wireless IP service using the geographical information of a mobile user, i.e., each application service using the position of a mobile device. This definition describes LBS as an intersection of three technologies (Figure 1).

Figure 1. Location-Based Services (LBS) as intersection of three technologies.

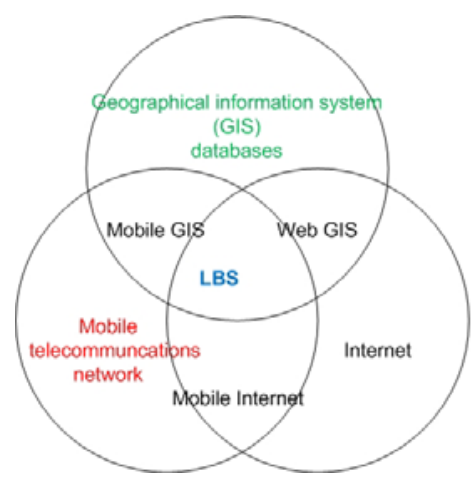

LBS is a fast-growing research field with the potential for high revenues in the mobile devices of tomorrow. LBS are already used in global mobile commerce for various application domains, including intelligent navigation support, transport logistics, mobile working environment, geo-fencing, parental supervision, rescue/emergency support, location/context-based events, and spatial information systems [3]. According to ABI Research, the number of subscribers to handset-based location-based services increased in 2008 to more than eighteen million [4]. Swedish analysts from Berg Insight also forecast a growth of the location-based service revenues in Europe from €220 million in 2009 at a compound annual growth rate of $12 \%$ to reach $€ 420$ million in 2015 . Local searches, navigation services and social networking are believed to become the top applications in terms of user numbers. However, many users are still little or not yet aware of the myriad of possibilities in the field of 
Location-Based Services, and there are also many open issues, unsolved technical challenges, and tradeoffs between cost and quality of service still to be dealt with before LBS field matures.

Various market studies [5,6], demonstrated that location-based services (LBSs) on future mobile phones (e.g., smart phones) will become a huge market in the next five-ten years. The positioning engine on a mobile device can be based on one or several of the following location technologies: Global Navigation Satellite Systems (GNSS) location, Wireless Local Area Networks (WLAN) or Bluetooth location, cellular technologies, vision navigation, Signals of Opportunity (SoP) location, etc. Most likely, hybrid solutions combining these techniques will provide the desired accuracy, coverage and reliability in the future. Some key questions regarding future LBS are: What is the accuracy desired by the user in the context of various applications? Which scenarios are the most important from the user point of view? and What kind of allowances (e.g., in terms of cost, size and battery consumption) the user is willing to make for an improved LBS application? It was shown in [7] that the challenge in the LBS field for researchers is to demonstrate attractive potential for LBS applications, while the challenge for the industry is to deliver the elements needed at a price the consumer and business users can accept.

Hence, one of the important issues to investigate is the end-user perspective on location-based services and related issues, such as additional costs and battery consumption, enhancement of social wellbeing due to LBS, and privacy concerns. Currently there are not many available studies (such as [1-3]) dedicated to the end-user perspective on these topics. This paper offers a new approach to the subject, by investigating the views of young users of LBS, who represent an important market for emerging technologies [8]. The purpose of this article is to shed some light on these user-related concerns and perspectives, based on two extensive surveys among university students at Tampere University of Technology (TUT), Finland and at University 'Politehnica' of Bucharest (UPB), Romania. The students from both universities were majoring in telecommunications or signal processing at the time of the study.

The study was organized as a 16-page survey with multiple-choice questions as well as an open-ended part for each question, where the respondent was able to input his/her own thoughts about the addressed topic. The initial questions were drafted in English and, after reviewing for clarity and conciseness, they were translated into Romanian with a number of revisions: terms were clarified, the layout of the questions was reorganized, and additional instructions were added where necessary. The results are based on 105 responses of students with ages varying between 20 and 31 years old.

To the best of the authors' knowledge, our results are rather unique in the literature dedicated to mobile location-based services as seen from the users' point of view, since we could find no other reported questionnaire that focuses on users' needs and wants in the context of mobile location and derived LBS. A survey about German users' willingness to adopt LBS and about their stated LBS user experience was published in [9]. While user privacy concerns in the context of LBS have also been tackled in $[9,10]$, these articles did not consider the other issues we address here, such as desired features and LBS applications on a navigation wireless receiver, user interactivity assent in the context of mobility and cooperative networks, or perceived utility of LBS in the context of social wellbeing. A user perspective of LBS was also discussed in [11], but only from the author's point of view; user survey results were not included to support their assertions. 
The remaining sections of this paper are structured as follows: The second section briefly specifies the methods and subject background of our survey. The third section shows the results of the questionnaire, grouped into 6 classes with respect to location-based services on the mobile device: desired user features, desired LBS applications, users interactivity assent, privacy concerns, youngsters' perceived LBS drivers, continuous location and mobility models, and LBS-driven increased social wellbeing. The fourth section focuses on the correlations between the two studied groups. It will be shown that users' preferences in the two groups are generally similar, despite the geographical differences. The fifth section presents some design issues and implications to take into account in the light of the studied users' perspectives and wishes, while the last section summarizes the main findings.

\section{Purpose of the Study and Methodology}

\subsection{Objectives}

We conducted a survey among BSc and MSc level students at two technical universities: University "Politehnica" of Bucharest, Romania (UPB), and Tampere University of Technology Foundation, Finland (TUT). The total number of responses was 109 (out of 136 registered for the lectures). Four respondents did not agree to allow the use of their answers in anonymous statistical analysis, and therefore we have based our analysis here on 105 answers (58 from Finland and 47 from Romania). The students coming from TUT were foreign students in exchange programs and had various backgrounds (13 different nationalities from all over Europe and Asia: Bangladesh, Bulgaria, China, France, Germany, Greece, India, Italy, Pakistan, Poland, Russia, Turkey, and Spain). The students at UPB were all Romanian. The survey was performed during October-December 2010. It was sent in electronic form to students and they returned the filled questionnaire either on paper or as an attachment to an email. The students were motivated to answer the questionnaire by getting bonus points for the exams. There is arguably a self-selection bias due to the choice of students answering the questionnaire. However, we noticed that all students actively attending the lectures were also those who participated in the questionnaire, and thus, the bonus point motivation seemed not to bring any extra incentive to the selected sample. The students were at BSc or MSc level, all of them undergoing a university major in wireless telecommunications or signal processing.

Our survey addressed the six main issues enumerated below:

- What are the most important features, from the end-user's point of view, of a mobile terminal with location capabilities? (Such as, accuracy, cost, size, delay, user interface, device design, screen size, continuous location capability, etc.).

- Which are the main LBS and location scenarios which users are likely to pay money for in the future, and which applications would they like to see on their mobiles in the future?

- On how much interactivity we may count on from the users' part in future designs employing enhanced location accuracy, mobility models and cooperative networking?

- How serious are the privacy concerns from the user's point of view, in the context of several scenarios?

- What is the end-user's opinion regarding the top user classes of future LBS? 
- What kind of LBS may improve social wellbeing in the user's perception?

\subsection{Respondents' Background and Familiarity with Navigation Systems}

The average age of the respondents at TUT was 24 years (average 24.41, std 2.72, $\min 20$, max 31), and the average age of students at UPB was 23 years (average 23.12, std 1.09, min 21, $\max 27$ ). The total average age for the 105 respondents was 23.83 . The percentage of females among TUT students was $20 \%$ and among UPB students was $40 \%$. Their level of knowledge regarding various location technologies employed or under research nowadays is illustrated in Figure 2 (related to satellite-based location systems: GPS, Galileo, Glonass, Compass, and EGNOS) and Figure 3 (related to non-satellite positioning technologies: WLAN, RF-ID, Vision navigation, Signals of Oportunity SoP, and Cellular-based positioning). Most of them were very familiar with GPS, as expected. Less than 50\% have moderate-to-good knowledge about any other positioning system or technology except GPS. Newer techniques such as those based on Signals of opportunity (SoP) and RF-ID were in fact very poorly known. A comparison between the two student groups showed that the UPB students confessed to know (on average) a little bit more than those at TUT about Galileo, Glonass, Compass, WLAN and cellular-based positioning, while those at TUT were slightly more familiar with GPS, RF-ID, Vision-based and SoP location techniques (however, the only significant difference was related to RF-ID knowledge, $p$-value $p=0.052$ via an unpaired t-test at a 5\% significance level 5).

Figure 2. Familiarity level with satellite navigation systems.

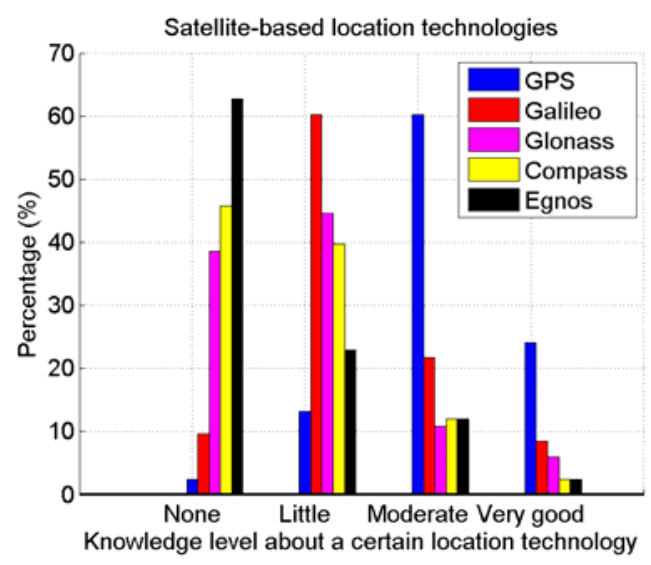

Figure 3. Familiarity level with non-satellite navigation systems.

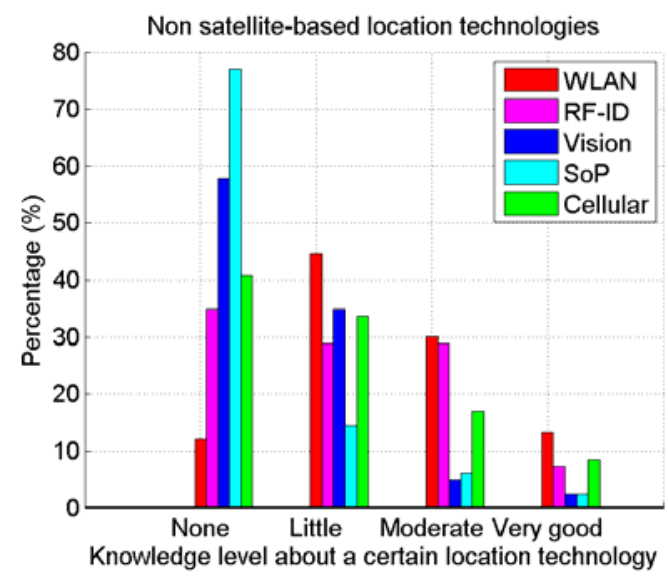


Based on Figure 2, we noticed that Galileo is still rather poorly known among the students at these two technical European universities.

In fact, the confessed level of knowledge about various positioning systems was surprisingly low, given the respondents' technical background in wireless communications and signal processing. The level of knowledge in this area looks (intuitively) similar to that of any other person with a general technical background (not necessarily in wireless communications).

Regarding the number of owned mobile devices, the interviewed students owned, on average, at least 2 mobile devices (such as mobile phone, laptop, GPS unit, or cordless phone), as illustrated in the histogram from Figure 4. Only two of them (both from UPB) wrote that they do not own any mobile device.

Figure 4. Number of wireless devices owned by the respondents.

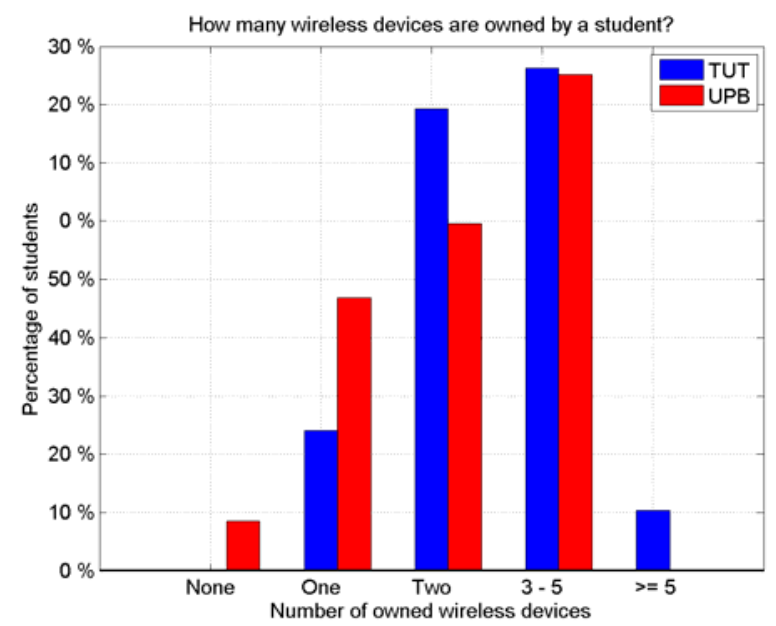

\section{Survey Results}

\subsection{LBS Applications and Desired Features}

Ten categories of possible LBS applications have been presented to the interviewed students and they were asked to evaluate how much (in addition to what they are currently paying monthly for their mobile subscription) they would be willing to pay for having a location-based service belonging to each of those ten possible LBS categories on their mobile. Their willingness to pay was measured on a 1 to 5 Likert scale with 1 corresponding to $0 \%$ extra, 2 to up to $1 \%$ extra, 3 to up to $5 \%$ extra, 4 to up to $10 \%$ extra and 5 to up to $25 \%$ extra (compared to their current mobile fee subscription).

The ten LBS categories were: (1) applications related to social interactions and networking (e.g., finding out where own friends are, location-based reminders, etc.); (2) applications related to automatic road tolling and road taxes (e.g., automatically paying the road tolls, based on the used highways, bill sent home); (3) applications related to increased social wellbeing (defined here as: health and fitness advices based on mobility patterns, child or pet tracking, lost item tracking, etc.); (4) applications related to decreased pollution and a more eco-friendly environment (e.g., getting location-based information about congested roads and alternative routes, getting information about average speeds recommended in various zones in order to decrease pollution, etc.); (5) applications related to navigation and route planning (e.g., multimedia guide when visiting a new town, with 
information updated according to own location, finding out about cultural/sports events nearby); (6) applications related to entertainment/infotainment (e.g., mobile games tailored to own location and/or movements); (7) applications related to natural disasters (e.g., getting information about the probability of an earthquake, a tornado, a Tsunami, etc. at current location); (8) applications related to emergency situations (e.g., getting faster help in the case of a road accident, being informed when a friend/ relative needs emergency help, etc.); (9) mobile advertising (e.g., if someone wants a product in a specialized store, let's say a camera, he or she could receive the offers from nearby shops that are also selling cameras, just by pointing their own camera phone at the wanted product, or just by storing information on their own phone about the searched product); and (10) geo-tagging (e.g., automatically adding geographical metadata, such as location information, to their own digital picture). The results (based on the average of the 105 answers) are shown in Figure 5. The histogram of the results is shown in Figure 6.

The most attractive application areas for the respondents were related to emergency, navigation and wellbeing. Social networking came only in sixth place, after applications related to disaster forecast/announcements and pollution decrease. The areas for which the users are most reluctant to pay extra are those related to advertising, infotainment and geo-tagging. This is also in accordance with the findings in [12], where it was stated that a successful LBS must address a real need for users and that "nice-to-have" applications, such as those related to advertising and geo-tagging may be insufficient to sustain a business case.

Figure 5. LBS significance for the end user, measured as willingness to pay extra compared to the current monthly fee; average values: (1) maximum $0 \%$ extra; (2) maximum $1 \%$ extra; (3) maximum 5\% extra; and (4) maximum 10\% extra.

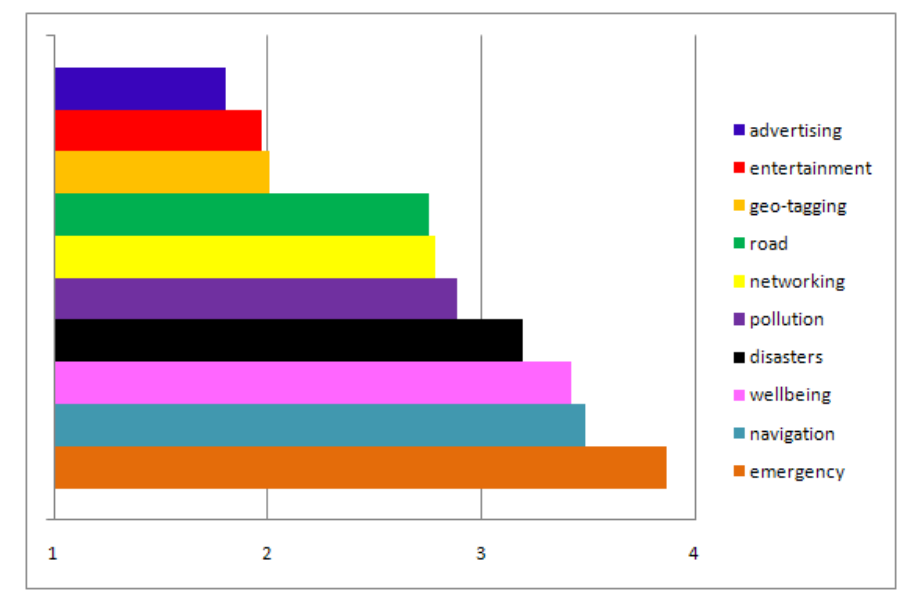

Interestingly, as seen in Figure 6, more than $45 \%$ of the respondents were willing to pay up to $25 \%$ more than what they are currently paying for their mobile subscription in order to have a good emergency location service active (e.g., faster help available when needed or being able to offer help to friends in need). Emergency location services are nowadays typically offered for free on location-enabled phones, but the answers here suggest that better, personalized emergency LBS (e.g., getting information about friends/family in need) have a great potential to attract consumer revenues. 
Figure 6. Histograms of preferences about possible LBS on personal mobile phones, measured as willingness to pay an extra monthly fee.

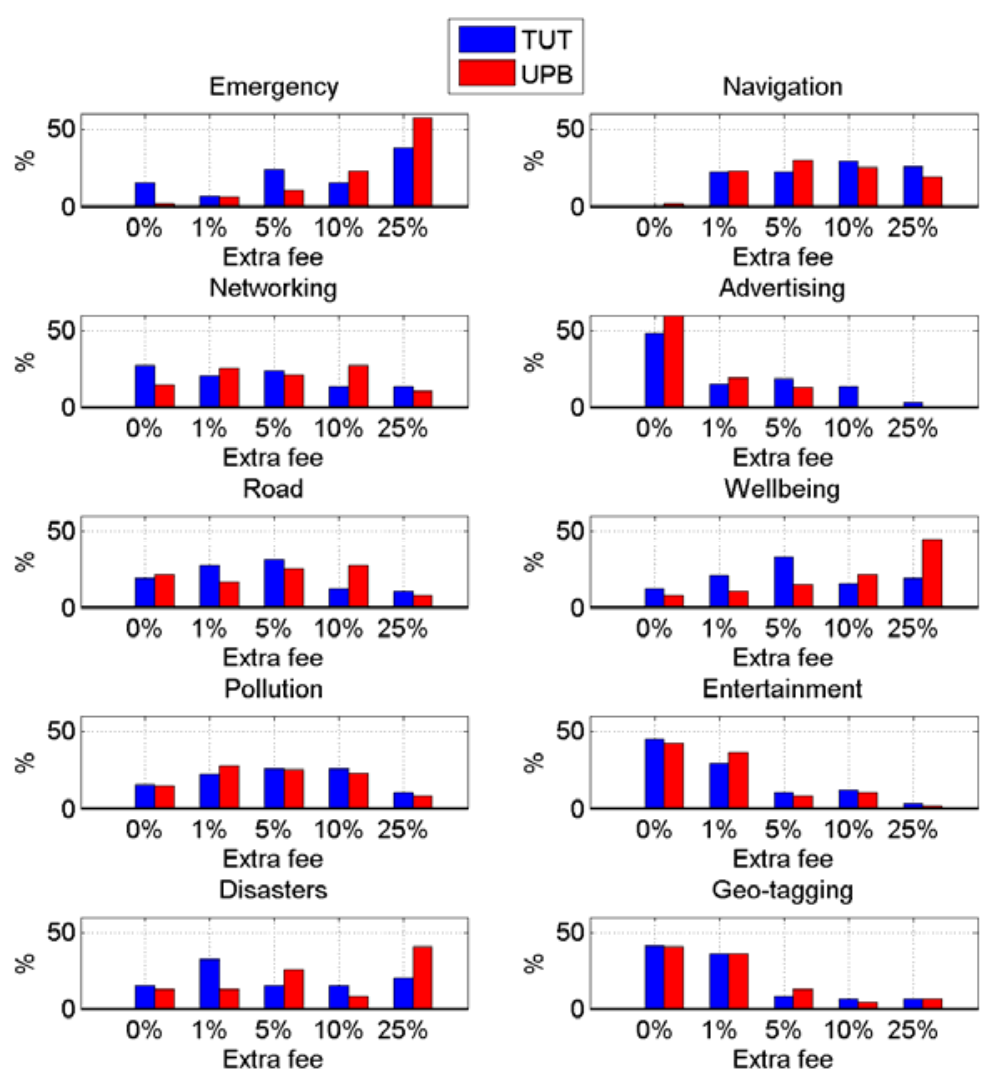

The applications related to navigation (road navigation, personal navigation) which are the current major business models for positioning-enabled mobile devices remain in the top three preferences of the users, with $53 \%$ of interviewed students being willing to pay more than $5 \%$ extra for enhanced navigation and route planning services. These results concur with the conclusions of the survey presented in [2], which also addresses the opinions of third-year university students. Rather surprisingly, the category defined by us as the 'wellbeing' category (including all sorts of applications meant to increase the physical/health or emotional status of the user) is seen with great interest by the students and $51 \%$ of interviewed students are willing to pay more than $5 \%$ extra (and up to $10 \%$ or $25 \%$ extra) for such applications.

Social networking via LBS seems somehow important, but not as important as LBS related to pollution decrease; natural disasters forecast and increased wellbeing. This is an interesting finding given the respondents' age; one would have expected social networking to be most important in this age category; however, it appears that the study group may prefer other forms of interaction to the virtual one (e.g., verbal, face-to-face, mailing, etc.).

On the bottom of the scale, the students were most reluctant to pay extra for advertising, infotainment/entertainment and geo-tagging, and the preferences in the two study groups were similar regarding these applications. As seen in Figure 6, advertising seems to be acceptable only as a free service for the vast majority of the users, even if such advertising would bring them the benefit of getting a discount for the items they are looking for $(60 \%$ of them confessed that they are not willing to pay anything for location-based advertising). In our opinion, this is related to the current 'advertising' 
culture, where advertising is free for the end-user and users have difficulty in choosing the required offer among the myriads of offers. The pre-defined user perception of 'advertising' is still something to be worked at and improved, in such a way that advertising starts to be tailored to user-needs (by allowing the user, for example via an easy-to-use search engine, to define what she or he is looking for). The infotainment/entertainment applications also seem to be areas with little potential of revenues for youngsters $(46 \%$ of the students are not willing to pay anything extra for such services, and $80 \%$ of them are not willing to pay more than $1 \%$ extra). The market segment for such applications might be higher for children and high-school teenagers.

The importance level of various features embedded in the mobile device in the context of navigation is illustrated in Table 1. Here, the respondents were asked to evaluate the features of a mobile device with LBS capability that they would like to buy on a Likert scale from 1 (not important) to 4 (very important). They were also requested to avoid checking all these features as very important, and to think about the relative importance of one feature versus another. The features are shown in Table 1 according to a decreasing level of importance (based on the mean of the responses).

Table 1. Importance levels, assigned by users, to several mobile device features in the context of LBS, on a scale from 1 (not important) to 4 (very important).

\begin{tabular}{|c|c|c|}
\hline & Mean & $\begin{array}{l}\text { Standard } \\
\text { deviation }\end{array}$ \\
\hline Low cost of the monthly subscription fee to a certain service & 3.67 & 0.56 \\
\hline Long battery life/ low power consumption & 3.66 & 0.58 \\
\hline Device robustness (i.e., not fragile when dropped, when wetted, when hit with a strong object, etc.) & 3.52 & 0.69 \\
\hline Low cost of the mobile device & 3.2 & 0.81 \\
\hline Large screen/display of the mobile device & 3.09 & 0.77 \\
\hline User friendliness (e.g., ease of use of a certain location-based application on the mobile device) & 3.07 & 0.79 \\
\hline Moderate accuracy of the location position (e.g., average errors less than few tens of $\mathrm{m}$ ) & 2.91 & 0.80 \\
\hline $\begin{array}{l}\text { Very high availability of the position estimate (e.g., to be able to receive the location estimate } \\
\text { in more than } 98 \% \text { cases) }\end{array}$ & 2.90 & 0.80 \\
\hline Moderate availability of the position estimate (e.g., in more than $70 \%$ cases) & 2.90 & 0.80 \\
\hline Light weight of the mobile device & 2.8 & 0.85 \\
\hline $\begin{array}{l}\text { Small amount of manual settings (e.g., adjustments in the application settings according to } \\
\text { location to be done automatically as far as possible) }\end{array}$ & 2.71 & 0.97 \\
\hline Short delays (e.g., time to start a certain location-based application on your mobile) & 2.68 & 0.92 \\
\hline Very high accuracy of the location position (e.g., average errors less than $1 \mathrm{~m}$ ) & 2.56 & 0.86 \\
\hline Small size of the mobile device & 2.58 & 0.84 \\
\hline $\begin{array}{l}\text { 'Cool' design (e.g., elegant design of device, originality of the presentation for a certain } \\
\text { application, such as funny voice for giving directions, possibility of interactivity with the } \\
\text { device, etc.) }\end{array}$ & 2.35 & 0.96 \\
\hline
\end{tabular}

The top three features from the end-user point of view proved to be: the cost of the monthly subscription to a certain LBS service, the battery life and the device robustness. Interesting enough, the bottom three features in the students' view are the 'coolness' of the design, the small size and a high level of accuracy in the location solution (meaning that most users are satisfied enough with a moderate accuracy level, in the region of a few tens of meters). The histograms of the top and bottom two features are also shown in Figure 7. 
Figure 7. Histograms of preferences regarding the top and bottom two mobile device features in the context of mobile positioning.
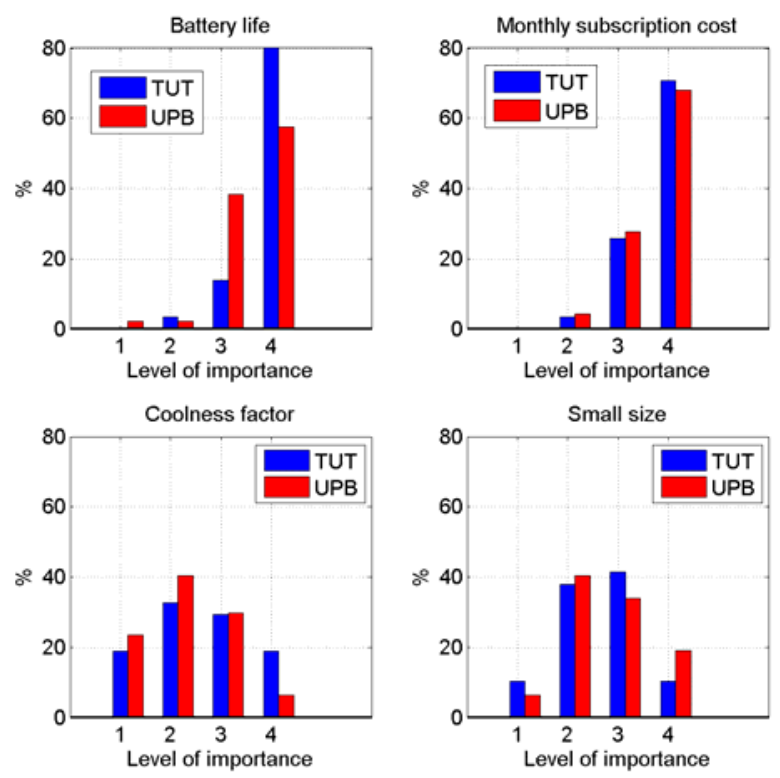

As expected, more than half of the respondents assigned maximum importance to the battery life and monthly subscription cost. On the other hand, the features with the smallest average, such as 'coolness factor' and small size, showed a Gaussian-like distribution.

\subsection{Desired LBS Applications and Target Scenarios}

\subsubsection{Suggested Applications}

When asked in an open-form question about their desired LBS applications in the future, the students' answers could be grouped in the following broad and non-exclusive categories:

- Navigation related: receiving timely information about bus/train/metro routes and timetables at the nearby bus/train/metro stops, pedestrian guidance in a new town based on 'safety' (e.g., based on information about criminal records in that area from the past and based on current status regarding closed routes, accidents, etc.), information about the traffic jams when driving.

- Emergency related: getting information about friends in need and getting timely help when in an emergency situation, getting forecasts about disaster likelihoods in nearby areas.

- Remote monitoring and tracking: controlling industrial parameters over the mobile device; mobile office.

- Local search: localizing shops with certain desired products in an area nearby, request nearest business or service (ATM, hospital, hotels and restaurants according to ratings, public toilet, etc.), finding out the location of a friend, a child or a relative that you are supposed to meet with, that you are searching for or that you are talking by phone with (within this survey, the issue of the other user's consent was not addressed), finding out opening times of shops nearby, localizing lecture /conference rooms in an institution.

- Automatic check-in: automatic payment for tickets based on mobile identity. 
- Enhanced personal wellbeing: help in personal planning (e.g., regarding routes to take in order to minimize the time and visit all desired places within a day), health advice (e.g., weekly statistics about own traveled routes and speeds as a pedestrian and recommendations towards healthier walking habits), being able to order some food and drinks in advance via mobile device at a location nearby, where the user will arrive shortly, mobile device reminders (what items to remember to take) based on the planned destinations.

- Enhanced social wellbeing: decreased pollution through a monitoring traffic system that gives feedback to the drivers about recommended routes and speeds, intelligent vehicles with location/movement sensors that may diminish the probability of collision/accidents, cooperative positioning.

- Security and authentication: Authenticated Positioning Service-while making a transaction over the Internet from mobile device (or with PayPal or home banking) positioning information could be added for legal concerns. The user can preset some settings for the allowed area to use for a certain time. The user receives a certificate from a trusted third party as a proof of position. This could be a good application for commercial service of Galileo, if it would be the case. Third party verifies the position, velocity, time (PVT) estimate and issues a certificate including proof of position for ID.

- Advertising: being informed of the local discounts nearby (regarding this issue, the users' opinions were divided between those who would like to receive information about all possible discounts while in a Mall or a shopping place, and those who would like to get information only about the items they are searching for)

- Other suggested applications: maintaining equidistance between planting in agricultural sector, sharing taxi cabs and automatically sharing the costs between the unknown passengers based on their desired traveled routes, automatic brake systems in cars based on detection of a nearby dangerous curve or traffic jams.

\subsubsection{Mobility Models and Continuous Location}

Figure 8 shows the results when the surveyed students were asked about the importance of having accurate location in one of the following five scenarios:

- at high speeds (e.g., above $50 \mathrm{~km} / \mathrm{h}$, by car in rural areas, on highways, or by train at high speed).

- moderate speeds (below $50 \mathrm{~km} / \mathrm{h}$ ), e.g., when travelling by car in urban areas.

- when stationary (e.g., sitting on a bench in a park, or standing at a crossroad) or at pedestrian speed (when walking).

- in outdoor situations (on a highway, on the beach, walking down the streets, etc.).

- in indoor situations (in a shopping mall, at home, in a museum, etc.).

Accurate location was defined as meter-level accuracy. The most important scenario from the students' point of view was outdoors, in stationary case or at moderate speeds, pointing towards tourist-related applications. $62 \%$ of the respondents gave none or low importance to indoor location applications, and $37 \%$ of the respondents gave none or low importance to location applications when travelling at high speeds. 
Figure 8. Importance of having very good location accuracy in various scenarios.
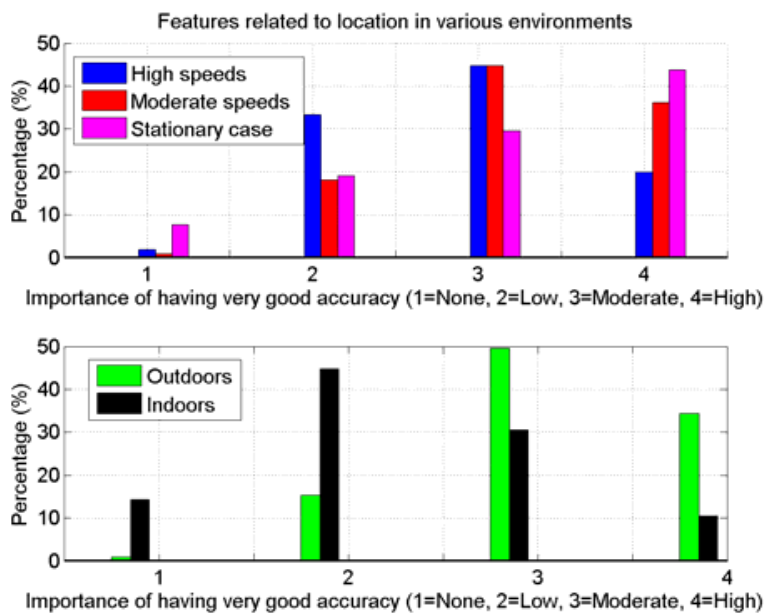

While tremendous effort is directed nowadays towards enhancing location technologies indoors and offering accurate positioning to indoor users, the indoor location market is not seen as an important one by the interviewed students. In fact, most agreed that the most important scenario where they would like to have an accurate location estimate is outdoors, and when traveling at low to moderate speeds (below 50 $\mathrm{km} / \mathrm{h})$.

As seen in Figure 9, 85\% of all respondents would accept no more than 5\% extra power consumption in order to have a continuous location engine on their device and $44 \%$ would accept no more than $1 \%$ extra power consumption. Again power consumption appears to be a very important concern. In terms of weight and size of the mobile device, $69 \%$ agreed that they would accept up to $5 \%$ extra in either one of them, but many specified that not both simultaneously. The application speed (i.e., the time to open a new application on the device while the location engine is running) was the most important factor according to the students, and 88\% would accept no more than 5\% extra longer starting time of a new application.

Figure 9. User allowances in order to have the location estimation engine working continuously on your mobile device (and not only on demand). $1=0 \%$ allowance, $2=$ up to $1 \%$ extra; $3=$ up to $5 \%$ extra; $4=$ up to $10 \%$ extra; $5=$ up to $25 \%$ extra.

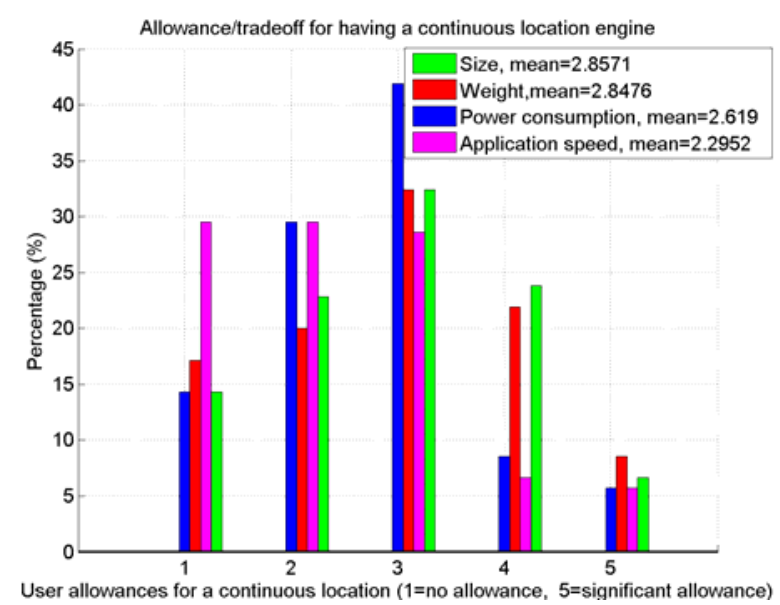




\subsection{User Interactivity Assent in the Context of Mobility and Cooperative Networks}

The students were also interviewed about their willingness to use an application on their mobile device that requires their feedback with respect to the position accuracy. For example, after using a while the navigation unit, the user would have the possibility to choose among 3-6 options, such as (i) perceived accuracy better than $10 \mathrm{~m}$ in most of the tested situations; (ii) perceived accuracy better than $50 \mathrm{~m}$ but worse than $10 \mathrm{~m}$ in most of the tested situations, etc. This willingness was measured on a Likert scale of 1 (none: no interest at all to use such application) to 5 (very often: very interested in using such application) and was shown in the legend of Figure 10 according to the following three scenarios:

- No bonus: willingness to give this feedback if the feedback is collected by the mobile operator and sent to the mobile manufacturers, such that future mobile devices can operate better (in this case, there would be no direct immediate advantage for the user; the only advantage would be that the user might contribute to the future consumers' wellbeing)

- Increased accuracy: willingness to give this feedback if the feedback can improve the position estimation the next time the user is using the device (e.g., via some adaptive methods already implemented in the device)

- Lower fee: willingness to give this feedback if the user gets some bonus points (e.g., reduction on your next bill) from own operator

The results are shown in Figure 10.

Figure 10. Willingness to give feedback regarding the location accuracy, conditioned to some incentives.

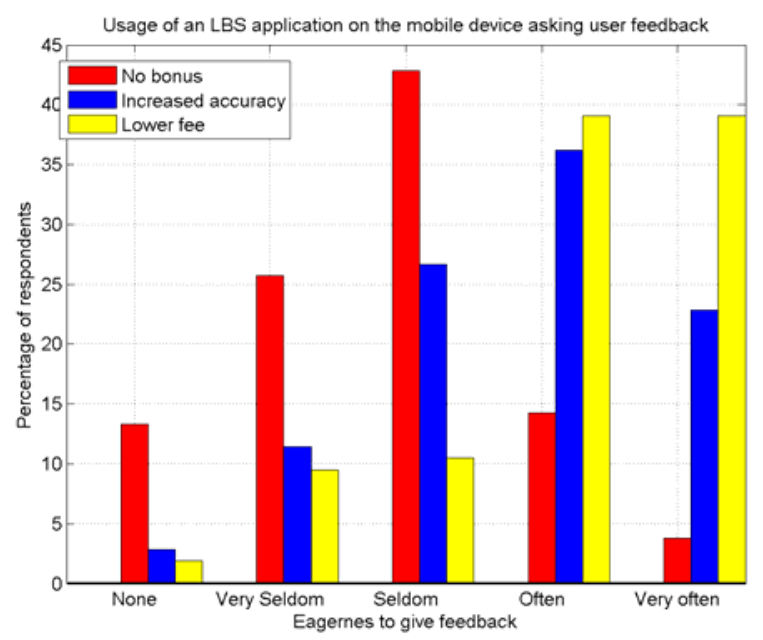

The 'Very seldom' option was defined as once per year, 'Seldom' as several times per year, 'Often' as several times per month, and 'Very Often' as several times per week. Clearly, the willingness to give feedback on a regular basis remains relatively low, even under some incentives such as better positioning accuracy or reduced fee (on average, a feedback around a couple of times per month related to the amount of incentive was measured).

The students were also asked if they are willing to spend some time when initially starting up each new navigation device in order to input information about where they are, assuming that this input 
would increase the accuracy of the position estimate at least a little bit. The input was to be given by choosing from a couple of options, such as (i) in a town, walking at small speed; (ii) in a town, driving; (iii) on a highway. There were three options for the answer: 'unconditional Yes', 'unconditional No', and 'Yes, only if the gain in accuracy would be very high' (e.g., 40\% better). The percentage of each of these answers is shown in Table 2.

The results match quite nicely with willingness to give feedback on the accuracy of the location estimate, as shown in Figure 10: between $20 \%$ and $30 \%$ of the students agree to interact with the mobile navigation solution (either in the form of a feedback, or in the form of an input about their mobility/scenario) if there is some accuracy gain (even small) envisaged, and more than $60 \%$ are interested in giving some input to help the positioning device if this would significantly increase the accuracy or if they would have a cost benefit. This signals the fact that navigation algorithms based on mobility models are likely to get significant input from the end-user, provided that good incentives are put in place, and mobility-model driven positioning algorithms are feasible options towards increasing the positioning accuracy.

Table 2. Willingness to give input when starting the navigation.

\begin{tabular}{lccc}
\hline & Yes & $\begin{array}{l}\text { Yes, if significant } \\
\text { gain in accuracy }\end{array}$ & No \\
\hline $\begin{array}{l}\text { Willingness to input mobility/scenario data to the location } \\
\text { engine every time they start the navigation engine }\end{array}$ & $29 \%$ & $62 \%$ & $9 \%$ \\
\hline
\end{tabular}

We have also looked at the correlation between users' willingness to pay more for various potential LBS applications and their willingness to give feedback without any bonus or incentive from the operator. In order to measure this correlation, the Pearson product-moment linear correlation coefficient (PPMC) was used. PPMC is defined as follows:

$$
P P M C=\frac{\sum_{i=1}^{N}\left(X_{i}-\mu_{X}\right)\left(Y_{i}-\mu_{Y}\right)}{\sqrt{\sum_{i=1}^{N}\left(X_{i}-\mu_{X}\right)^{2} \sum_{i=1}^{N}\left(Y_{i}-Y_{X}\right)^{2}}}
$$

where $X_{i}, Y_{i}$ are the Likert scores of user $i$, regarding the considered questions $(X$ and $Y), \mu_{X}, \mu_{Y}$ are the sample means and $N$ is the sample size or number of respondents (here $N=105$ ). It appears that there is none or very small negative correlation between the users' willingness to give feedback without bonus and their willingness to pay more for navigation or wellbeing applications (a PPMC correlation coefficient ranging from -0.01 to -0.09 ) and a positive correlation between users' willingness to give feedback without bonus and willingness to pay more for applications related to networking, disasters forecast and advertising (PPMC correlation coefficient between 0.11 and 0.18 ).

Asked whether they would be willing to allow cooperative positioning at the expense of battery consumption, but with the benefit of an increased accuracy (i.e., transmitting own position information, calculated by own mobile device, to neighboring mobile devices, in such a way to enable a cooperative network where position location can be computed more accurately for each of the users), the respondents at TUT and UPB had rather similar preferences, as shown in Figure 11. The 
cooperative positioning concept is based on the idea that users' mobile devices are communicating between them (transparent to the user) and exchange location information with each other, in such a way to enable a better location of each user.

Figure 11. Allowance for extra battery consumption in the context of cooperative positioning.

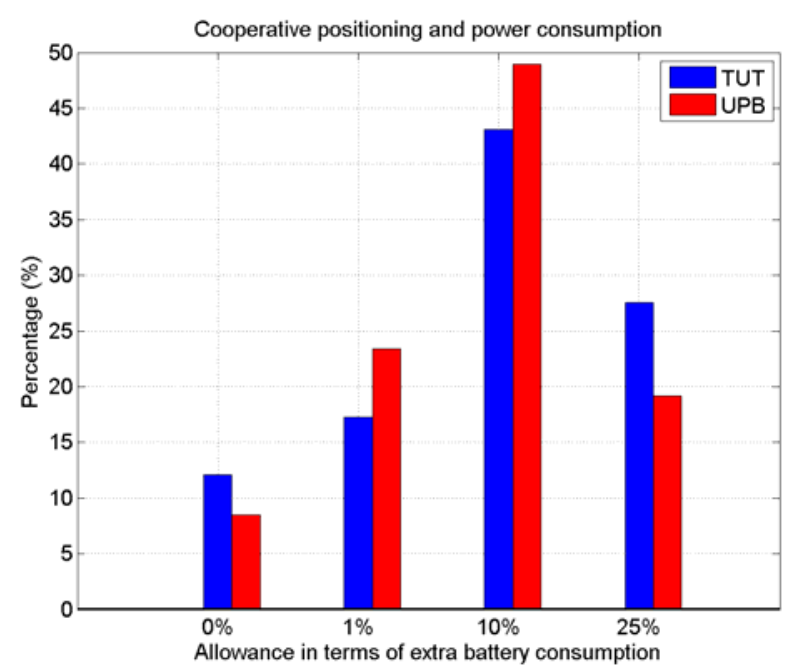

More than $40 \%$ of respondents in each group agreed to up to $10 \%$ extra battery consumption in order to enable a better accuracy via cooperative positioning. The idea of cooperative positioning seemed to have a great appeal within both groups; only about $10 \%$ of all respondents answered with a clear No (i.e., no extra battery consumption was acceptable to them) to the concept of cooperative positioning. This is a very interesting result regarding the perception of the users related to more advanced features, such as cooperative positioning, because, on one hand, users put a great emphasis on long battery times in their devices and not so much emphasis on a very high accuracy of the location solution (as seen in Table 1), but on the other hand they are willing to allow extra battery consumption to enable cooperation between the mobile players. This apparent contradiction can be explained by the fact that the idea of cooperative networks sounds very appealing to the end-user, giving him/her the feeling of belonging to a group and of increasing their general social wellbeing.

We detected a close-to-zero correlation (PPMC of -0.02) between the users' level of acceptance of cooperative positioning at the expense of their battery consumption and their willingness to give some accuracy-related feedback without any bonus. The correlation between their level of acceptance of cooperative positioning and willingness to give position accuracy-related feedback with some incentive is positive (PPMC of 0.18 if better accuracy based on their feedback and PPMC of 0.16 if some bonus from the operator).

When we studied the correlation between the users' level of acceptance of cooperative positioning at the expense of their battery consumption and their score regarding a long battery life in a mobile device with navigation utilities, the PPMC correlation coefficient was, not surprisingly, negative and equal to -0.15 . Also, the correlation coefficient between the users' preferences regarding long battery life and their willingness to trade off some battery life for a continuous location engine was negative $(-0.08)$. Indeed, this shows, as expected, that the users the most reluctant towards cooperative positioning and continuous location engines (at the expense of their battery life) are those who put the 
greatest emphasis on the battery life of the device. However, these negative correlation coefficients are not so strong, which points towards the fact that users' allowance towards battery consumption could be achieved, for example, through a better pointed-out user benefit in terms of accuracy, reliability or availability of the location solution.

We also detected a moderate positive correlation (PPMC of 0.40 ) between the users that would accept a shorter battery life in order to have a continuous location engine on their mobile phone and those who would accept a shorter battery life in order to enable cooperative positioning.

\subsection{Privacy Concerns}

In this section, a couple of issues regarding the privacy concerns of end users have been addressed. Firstly, by asking them to assume that they agreed upon giving some feedback regarding their location estimation accuracy, they were also asked whether they would agree that the mobile device sends this feedback to a third party, as mentioned in Table 3.

The vast majority (in both groups) had nothing against sending this information to their own operator and to the manufacturers of navigation-enabled mobile devices. However, if the third party was not clearly specified, most of them were reluctant to send this information. Similar privacy concerns were reported in [10]. The UPB students were much more comfortable than TUT students to send location accuracy-related data to their own friends rather than to unknown third parties, a fact that could be explained by an increased importance of social networking and competition with friends' situations and achievements in Romania, compared with other countries represented by the students at TUT.

Table 3. Consent to use the user feedback related to the location estimation accuracy.

\begin{tabular}{lcccc}
\hline & $\begin{array}{c}\text { Agree, } \\
\text { TUT group }\end{array}$ & $\begin{array}{c}\text { Disagree, } \\
\text { TUT group }\end{array}$ & $\begin{array}{c}\text { Agree, } \\
\text { UPB group }\end{array}$ & $\begin{array}{c}\text { Disagree, } \\
\text { UPB group }\end{array}$ \\
\hline $\begin{array}{l}\text { To own network service provider or to the } \\
\text { manufacturer of the navigation receiver, with the }\end{array}$ & $93 \%$ & $7 \%$ & $98 \%$ & $2 \%$ \\
goal of further enhancements of services & & & & \\
$\begin{array}{l}\text { To any unknown third party (e.g., research units, } \\
\text { newspapers, etc.) interested in the gathered data }\end{array}$ & $45 \%$ & $55 \%$ & $38 \%$ & $62 \%$ \\
$\begin{array}{l}\text { To own friends, for example in order to compare the } \\
\text { level of accuracy achieved with their mobile } \\
\text { devices }\end{array}$ & $52 \%$ & $48 \%$ & $64 \%$ & $36 \%$ \\
\hline
\end{tabular}

While Table 3 addresses the issue of the privacy of the location estimation accuracy, as perceived by the user, the next question also addressed the issue of the privacy of the actual location information. The students were asked about their consent whether the mobile operator can use their location information. Five variants were given:

- Yes: Don't mind at all/Don't care about 'being tracked'

- Yes, conditional, Cond1: Don't mind if that information is kept private by the operator and is used only in emergency situations; 
- Yes, conditional, Cond2: Don't mind if user can use some settings to define once in a while who is allowed to have access to own location information

- Yes, conditional, Cond3: Don't mind if the operator asks the user to give consent every time before distributing his/her location information to a third party

- No: Serious privacy concerns; do not agree with giving away the location information.

The answers are summarized in the histograms of Figure 12. Only 1 respondent (from UPB) had no privacy concerns whatsoever. $16 \%$ of the respondents at TUT and $25 \%$ of the respondents at UPB had very strong privacy concerns and did not agree with giving away their location information. The rest agreed upon a conditional Yes, that is giving away their location information in emergency situations or according to user-defined settings. The idea of being asked whether their location information could be used or not was very appealing among the students, which points out towards the fact that user privacy concerns could be overcome (to a certain extent) with some carefully appointed questions involving a certain amount of user feedback. The importance of user feedback in the context of online social networks and existing commercial systems for mobile location sharing has been in fact already emphasized in [13]. It was shown that user-defined settings are an important contributing factor towards improving user comfort levels and allaying privacy concerns, which is also in concordance with our findings.

Figure 12. Consent to third party to use location information, according to pre-defined user settings.

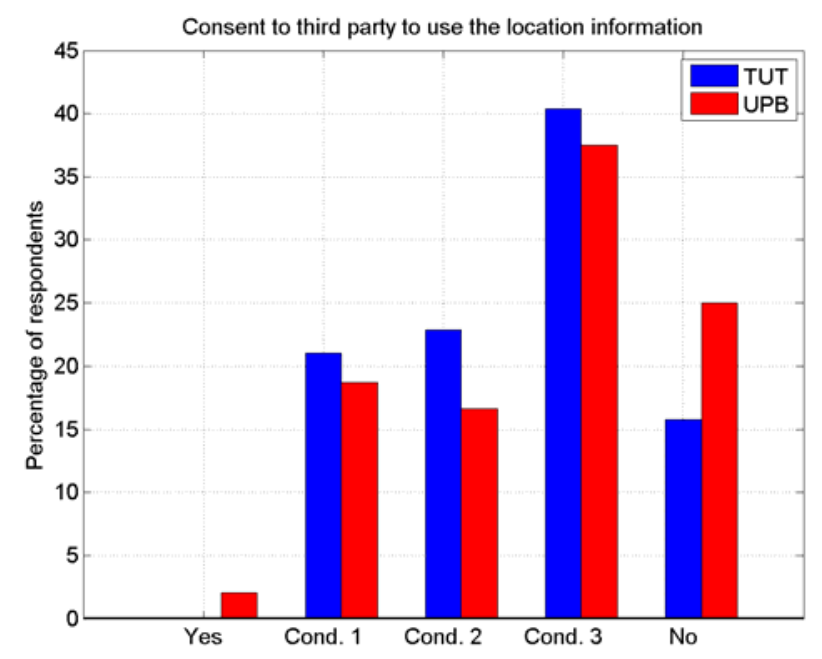

Based on the analysis on the PPMC correlation coefficients, we also noticed that the users who most value their privacy are also the users who most value a short delay in starting a new application on their mobile phone (PPMC of 0.17), the 'coolness' factor of their mobile device (PPMC of 0.15), and a small size of their mobile device (PPMC of 0.14). The users who are the least concerned about their privacy are the users who most value a moderate availability of their position estimate (PPMC of -0.14 ), a very high accuracy of the location position (PPMC of -0.13), and the robustness of their device (PPMC of -0.12). No correlation was detected between users' concerns about privacy and their preferences regarding the friendliness of their mobile device settings and the monthly subscription fee (PPMC of 0.03 in both cases). 
Regarding the privacy of their location information in various environments, dependent on their activity, the students were asked in which of the following cases they would authorize the access and subsequent usage of own location information:

- In emergency situations: when they are witnesses or involved in a car crash or other type of road accident (e.g., caused by thunderstorm, earthquake, etc.)

- When they are travelling abroad (e.g., their location data could be used for gathering statistics about people's mobility)

- When they spend their free time (pub, cinema, park, etc.)

- When at work

The histograms of the answers at TUT and UPB are shown in Figure 13. In emergency situations, $88.5 \%$ of the total of the respondents agreed that they would send their location information. The preferences regarding the travel abroad and during free time were rather unbalanced over the two groups: the group at TUT had significantly fewer concerns about sending their location information in these 2 cases. On average over the two groups, $83.91 \%$ disagreed to be tracked while at work.

Figure 13. Consent to third party to use location information, according to user activity.

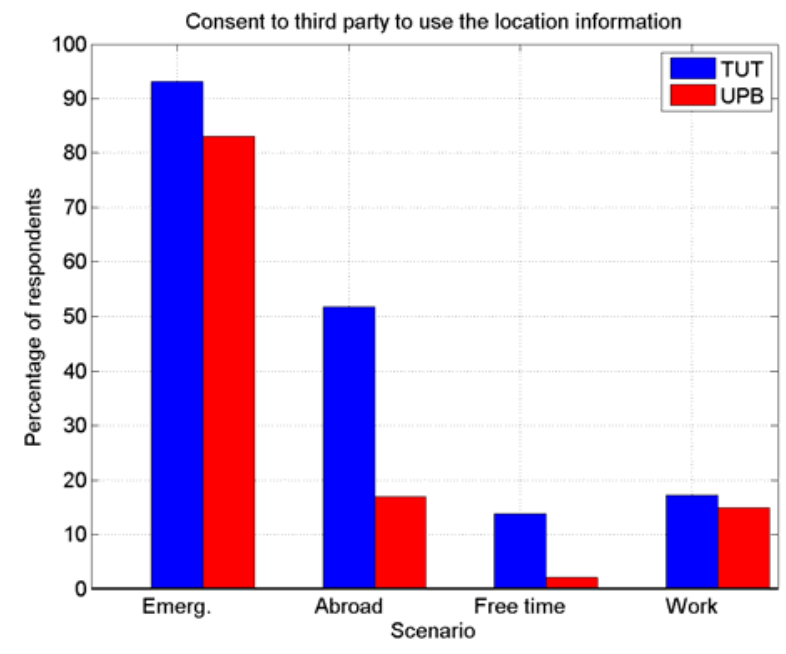

Most of the respondents ( $88.5 \%$ of all respondents) accepted to give their location to third parties in emergency situations, considering their safety more important than their privacy. In order to facilitate the user input in emergency situations, the manufacturers could for example equip their navigation receivers with some 'emergency buttons'. 36.19\% of all respondents also agreed to divulge their location estimation when abroad/traveling, and only $16.19 \%$ of them agreed to divulge this location information while at work. Most of them were most reluctant to divulge their location while spending their free time.

In the context of LBS applications currently in use, in August 2010 Facebook launched its geolocation "check-in" feature, 'Places' [14]. This feature, similar with other location-based services such as Gowalla and MyTown, allows the end-user to announce his/her presence at a bar, restaurant, park, or other location via Facebook. The students' opinion about the privacy-related and usefulness of similar geolocation-based services in the future is illustrated in Figure 14 and Figure 15, respectively. The privacy concerns remain rather high in both groups; only around $15 \%-16 \%$ in each group have 
none or low privacy concerns, while around $62 \%-65 \%$ in each group have high to very high privacy concerns.

The perceived usefulness of geolocation applications varies quite a lot among the respondents, the average was situated around a 'moderate' usefulness, but the preferences were rather normally distributed, especially within TUT group.

Figure 14. Privacy concerns in the context of geolocation applications such as Facebook 'Places'.

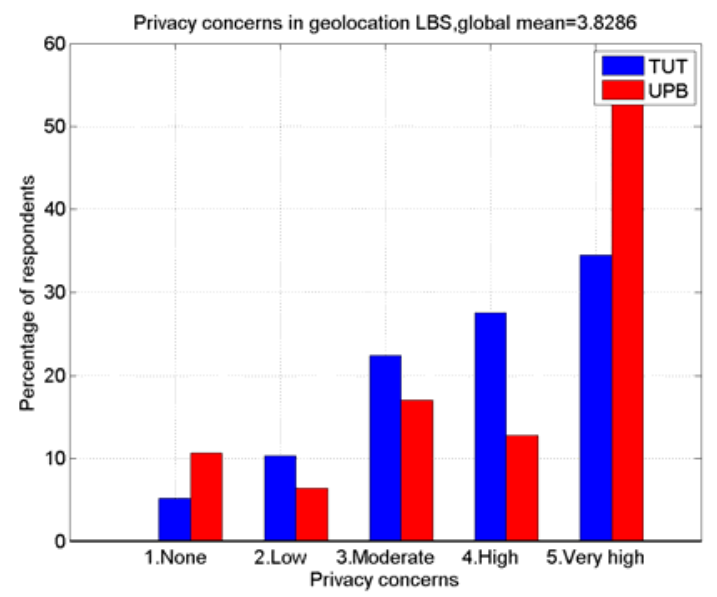

Figure 15. User-perceived usefulness of geolocation applications such as Facebook 'Places'.

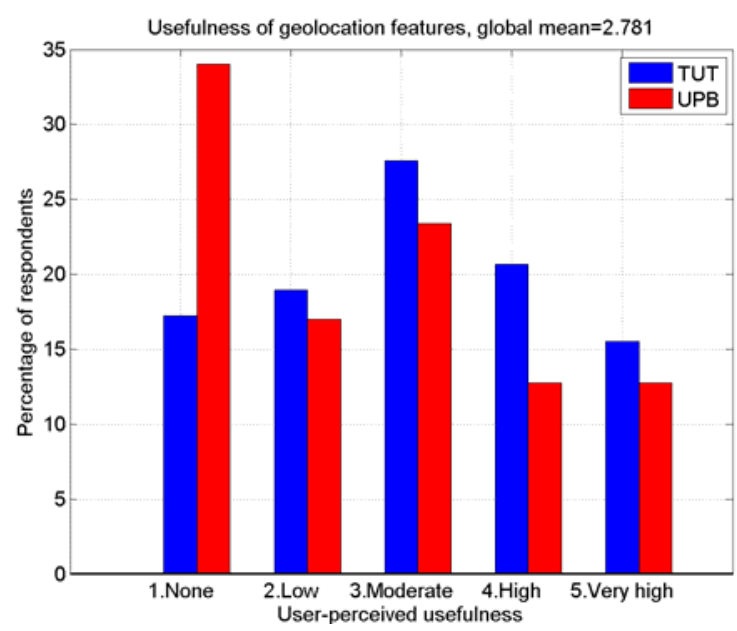

\subsection{Users’ Perceived LBS Drivers}

Asked their opinions about the future LBS drivers, only about $20 \%$ of the students believe that mobile advertising will bring revenue from the future LBS applications, while $76 \%$ agreed that local search for places of interest (e.g., finding out a shop, a bar, a cinema, a navigation route to another place, etc.) will likely be the main driver of LBS market also in the future (as seen in Figure 16). 
Figure 16. LBS market drivers according to students (the $\mathrm{x}$-axis percentages show how many agreed that this is a potential significant LBS market driver in the near future).

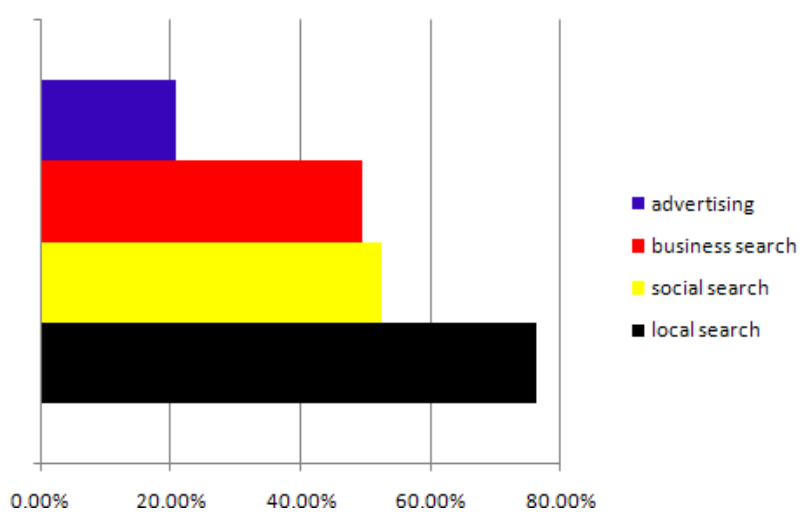

Regarding the business search and social search as possible LBS drivers, the votes were about 50\% affirmative (in here the students were asked to answer Yes or No to whether they believe that a certain class of applications, among those seen in the legend of Figure 16 is likely to act as an important LBS market driver and bring revenues in the future).

Asked their opinion about the importance (according to various user classes) of having mobile LBS applications in the near future, the students believed that tourists and fleet managers will be the main LBS users in the future, while teenagers and students are likely to form the user classes the least interested in LBS, as seen in Figure 17. An explanation of this fact is that the LBS applications are unlikely to come for free, and the perceived usefulness of LBS by the students is still rather low (as also shown previously in Figure 15).

Figure 17. Importance of future LBS applications for various user classes, as perceived by the respondents, on a scale of 1 (not important) to 5 (very important).

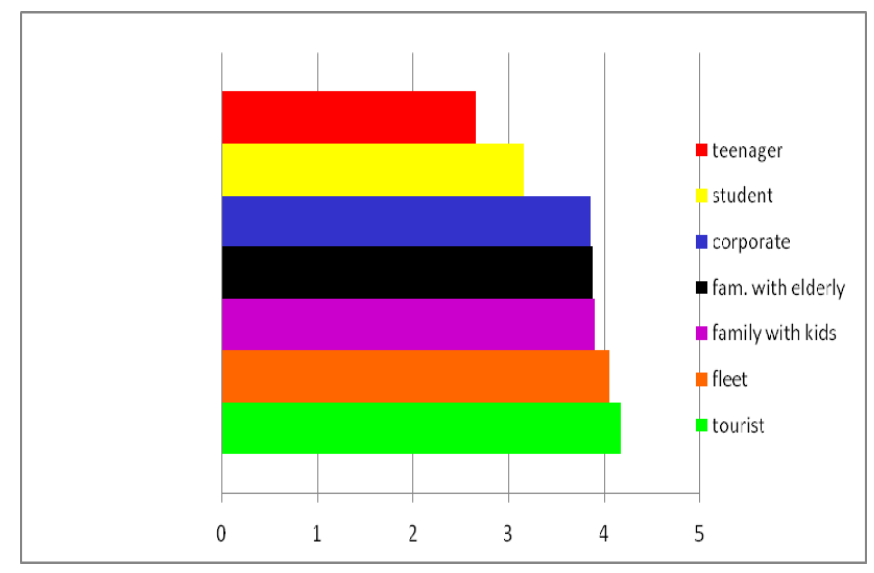

\subsection{LBS and Social Wellbeing}

The 'wellbeing' concept was tackled here from two angles: the first one referred to road-related applications and eco-friendly driving, and the second one presented a list of possible LBS areas to the students and asked them to associate a 'perceived social value' to each of them. 
The question regarding the LBS in the context of road applications/driving was framed in the context of an increased social benefit. The students where asked whether they would be willing to pay road taxes according to how much they drive (thus ensuring a fairer drive policy among people), if they would like to have automatic road tolls (e.g., to diminish the waiting time when passing through a toll point on highway and to diminish the congestion on highways nearby toll points), and if they would like to receive LBS assistance towards a more eco-friendly driving. The answers are summarized in Table 4. Surprisingly, a vast majority (82\%) are interested in a more eco-friendly driving. Also, the majority opted for automatic road tolls and pay-as-you-drive road taxes. The high percentage of neutral answers at the first two questions might be explained by the lack of a driving permit of those respondents.

Table 4. Users' opinions about the road tolling, road taxes and road-related location information in the context of LBS.

\begin{tabular}{lccc}
\hline & Agree & Neutral & Disagree \\
\hline Paying road taxes according to how much you drive & $60 \%$ & $21 \%$ & $19 \%$ \\
Paying road tolls only once or twice/year & $63 \%$ & $20 \%$ & $17 \%$ \\
Driving more environmentally friendly & $82 \%$ & $4 \%$ & $14 \%$ \\
\hline
\end{tabular}

Several options related to potential increased social wellbeing through LBS services were presented to the respondents (see the list below) and they were asked to check those on a Likert scale from 1 (no perceived social benefit) to 5 (see a lot of potential benefit socially):

- T-shirt displaying the position of the person who is wearing it (LBS T-shirt)

- Alert on your mobile about which metro/bus/tram is coming in the next 5 minutes in the location where you are (bus timetables)

- Getting a meal/drink for free in a restaurant/pub that you frequented often in the last year; the information about how frequently you visited a place is to be stored automatically in own mobile device, based on its location engine (free meal)

- Checking in automatically or automatic payment for a museum, train, theater show, etc., based on your mobile device with location capabilities; this would decrease the queues and waiting times (automatic check-in)

- Availability of location-based lotteries, such as, for example if municipalities or certain companies/ shops arrange a lottery where only the people located in a certain areas at a certain date can participate (lotteries)

- Possibility to track the location and movements of the significant other(s) with her/his/their consent (significant other)

- Existence of 'intelligent vehicles' that are aware of the positions and movement of people nearby and are able to prevent /reduce accidents (intelligent vehicles)

The average results are shown in Figure 18 (average of 105 answers) and the histogram of users' answers regarding this question is shown in Figure 19. 
Figure 18. Users' opinions about potential LBS that might increase social wellbeing. Scale from 1 (don't see any social benefits in terms of increasing the people wellbeing) to 5 (see a lot of potential benefit in terms of increasing people's wellbeing).

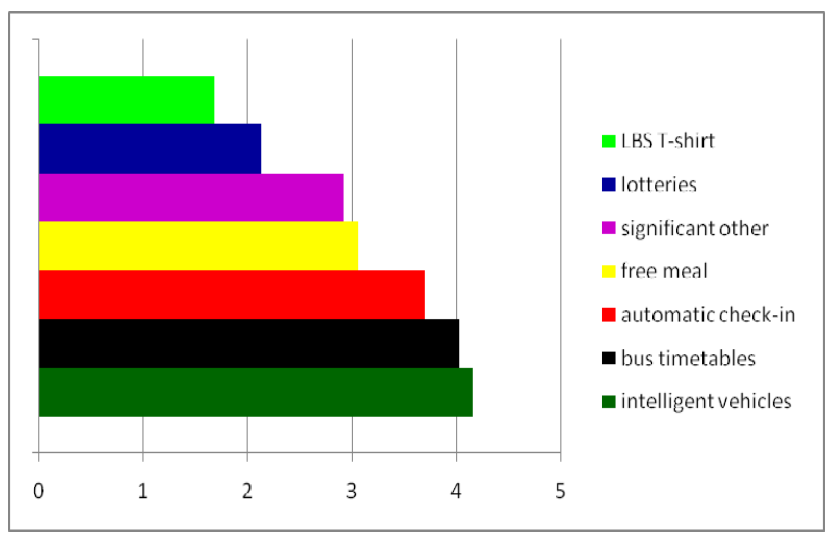

The top two location-based services/applications that would increase most the social wellbeing are, in the opinion of the interviewed students, those related to intelligent vehicles and receiving information about timetables of public transportation means. Automatic check-ins to various events/public places is also a very attractive feature. According to the interviewed students, the least interesting applications regarding their potential to increase social wellbeing, are, not very surprisingly, those related to individual gains, such as LBS T-shirt, location-enabled lotteries or tracking significant other(s).

Figure 19. Histogram of users' views regarding the potential increase of social wellbeing through various LBS.

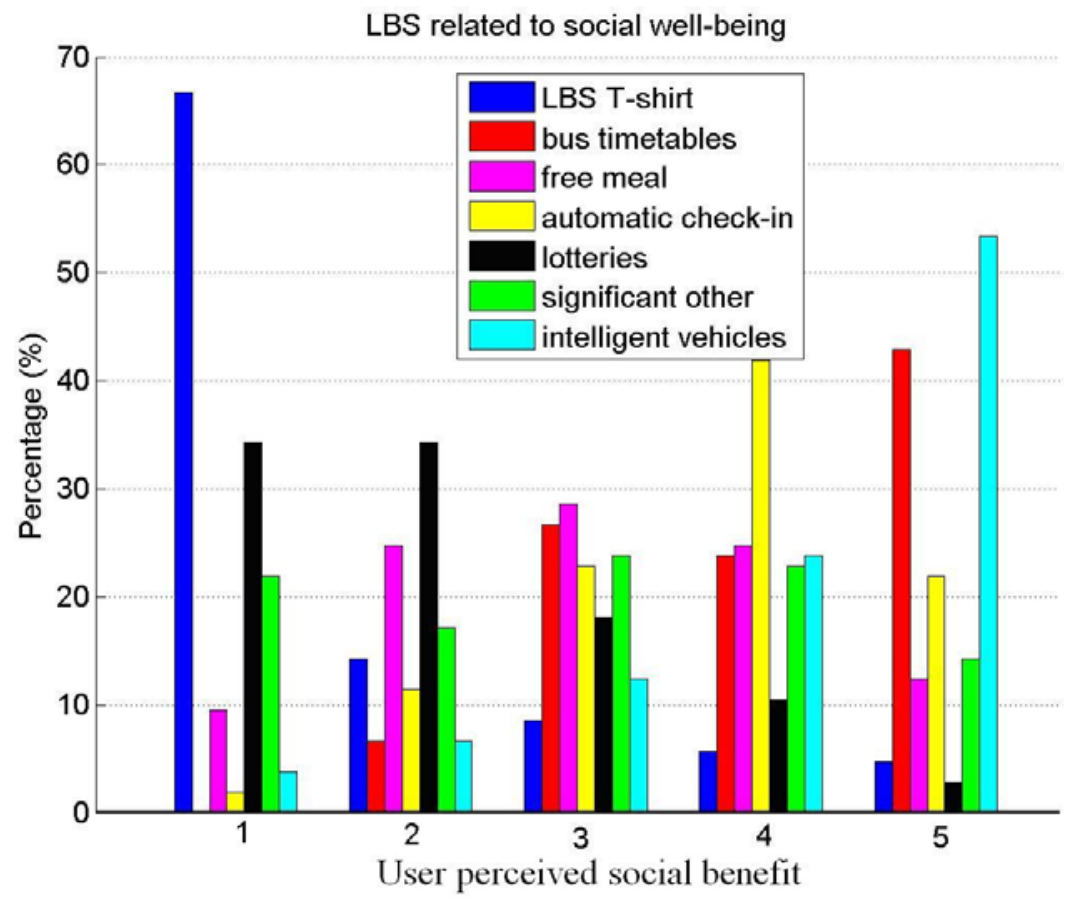

Regarding the timetables of bus/tram/metro/train stops nearby, all users agreed that this would increase social wellbeing at least a little bit, helping people to organize their routes better, to be less 
upset by long waiting times and to avoid discomfort by getting too cold or hot (weather-dependent) waiting at a particular bus stop. The intelligent vehicle concept and the possibility of diminishing accidents through location/motion detection sensors are very appealing to the majority of the respondents. Regarding tracking significant other(s) with his/her consent, the preferences are rather equally distributed on the 1-to-5 scale: $39 \%$ considered that tracking the significant other would be good (score 4 or 5 ) to society at large, while $41 \%$ considered this as having little or no social benefit (scores 1 and 2).

Interestingly enough, a positive correlation was detected (PPMC of 0.16) between the users that consider that being able to track the significant other may benefit society and those who had significant privacy concerns of their own.

\section{Comparison between the Study Groups}

Three different tests (for populations of unequal sizes) have been used in order to compare the TUT and UPB answers and to find out whether there is a statistically significant difference between the ratings of those attributes:

- The unpaired t-test (based on the assumption of normal distributions of populations) [15].

- The Der Waerden version of Mann-Whitney-Wilcoxon test (based on the assumption of equal variances of populations) $[15,16]$.

- The Fligner-Policello test (this test does not assume either normality or equal variances) [1719]. The rejection threshold in this case was computed at 0.025 .

The following hypotheses have been tested, at a 5\% significance (or alpha) level:

- $\mathrm{H0}$ - the two groups have similar preferences.

- Ha - the difference between groups is statistically significant.

All these tests compute the so-called p-value, the meaning of which is the following: a large p-value indicates that there is likely to be little (or no) population-related difference between the preferences; the smaller the p-value is, the more likely it is that the preferences of the two groups are statistically different. We will see that all three tests pointed towards similar conclusions.

The results are shown in Tables 5 to 8 , with respect to the following user preferences:

- Preferences related to mobile navigation device features (Table 5)

- Preferences related to acceptable user interactivity level (e.g., feedback and user-defined settings), shown in Table 6

- Preferences related to privacy (Table 7)

- Preferences related to social wellbeing (Table 8)

The last column in Table 5 to Table 8 shows whether H0 hypothesis is rejected or not at a $5 \%$ significance level with the Fligner-Policello test. 
Table 5. Correlation between TUT and UPB groups regarding mobile device preferences.

\begin{tabular}{lcccc}
\hline & $\begin{array}{c}\boldsymbol{p} \text {-value } \\
\text { for t-test }\end{array}$ & $\begin{array}{c}\boldsymbol{p} \text {-value for } \\
\text { Mann-Whitney test }\end{array}$ & $\begin{array}{c}\boldsymbol{p} \text {-value for } \\
\text { Fligner-Policello test }\end{array}$ & $\begin{array}{c}\mathbf{H}_{\mathbf{0}} \\
\text { rejected }\end{array}$ \\
\hline Battery & 0.01 & 0.006 & 0.0032 & Yes \\
Very high accuracy & 0.58 & 0.58 & 0.34 & No \\
Moderate accuracy & 0.22 & 0.20 & 0.10 & No \\
Very High availability & 0.91 & 0.86 & 0.48 & No \\
Moderate availability & 0.04 & 0.04 & 0.01 & No \\
Short delays & 0.96 & 0.92 & 0.47 & No \\
User friendliness & 0.11 & 0.10 & 0.04 & No \\
Small number of manual settings & 0.43 & 0.43 & 0.21 & No \\
Low cost of mobile device & 0.92 & 0.71 & 0.34 & No \\
Low cost of monthly subscription & 0.64 & 0.40 & 0.33 & No \\
Light weight & 0.20 & 0.20 & 0.07 & No \\
Small size & 0.39 & 0.38 & 0.24 & No \\
Large screen & 0.90 & 0.77 & 0.42 & No \\
'Cool' design & 0.12 & 0.12 & 0.06 & No \\
Device robustness & 0.64 & 0.40 & 0.25 & No \\
\hline
\end{tabular}

Table 6. Correlation between TUT and UPB groups regarding user interactivity level.

\begin{tabular}{lcccc}
\hline & $\begin{array}{c}\boldsymbol{p} \text {-value } \\
\text { for t-test }\end{array}$ & $\begin{array}{c}\boldsymbol{p} \text {-value for } \\
\text { Mann-Whitney test }\end{array}$ & $\begin{array}{c}\boldsymbol{p} \text {-value for } \\
\text { Fligner-Policello test }\end{array}$ & $\begin{array}{c}\mathbf{H}_{\mathbf{0}} \\
\text { rejected }\end{array}$ \\
\hline Feedback related to accuracy & 0.05 & 0.04 & 0.01 & Yes \\
Input regarding mobility/ scenario & 0.91 & 0.33 & 0.45 & No \\
\hline
\end{tabular}

Table 7. Correlation between TUT and UPB groups regarding privacy in the context of LBS.

\begin{tabular}{lcccc}
\hline & $\begin{array}{c}\boldsymbol{p} \text {-value } \\
\text { for t-test }\end{array}$ & $\begin{array}{c}\boldsymbol{p} \text {-value for } \\
\text { Mann-Whitney test }\end{array}$ & $\begin{array}{c}\boldsymbol{p} \text {-value for } \\
\text { Fligner-Policello test }\end{array}$ & $\begin{array}{c}\mathbf{H}_{\mathbf{0}} \\
\text { rejected }\end{array}$ \\
\hline $\begin{array}{l}\text { Feelings about 'being tracked' } \\
\text { Privacy concerns in geolocation } \\
\text { applications }\end{array}$ & 0.50 & 0.67 & 0.30 & No \\
\hline
\end{tabular}

Table 8. Correlation between TUT and UPB groups regarding increased social wellbeing in the context of LBS.

\begin{tabular}{lcccc}
\hline & $\begin{array}{c}\boldsymbol{p} \text {-value } \\
\text { for t-test }\end{array}$ & $\begin{array}{c}\boldsymbol{p} \text {-value for } \\
\text { Mann-Whitney test }\end{array}$ & $\begin{array}{c}\boldsymbol{p} \text {-value for } \\
\text { Fligner-Policello test }\end{array}$ & $\begin{array}{c}\mathbf{H}_{\mathbf{0}} \\
\text { rejected }\end{array}$ \\
\hline Ecological driving & 0.11 & 0.05 & 0.04 & No \\
Automatic check-ins & 0.86 & 0.83 & 0.46 & No \\
Public transport timetables & 0.09 & 0.08 & 0.03 & No \\
Intelligent vehicles & 0.24 & 0.16 & 0.11 & No \\
\hline
\end{tabular}

Based on the findings, it seems that the hypothesis that users in the two studied groups have similar preferences cannot be rejected in the majority of cases. The only two cases where users are likely to 
have dissimilar preferences are with respect to battery life and with respect to user feedback (e.g., regarding positioning accuracy). Indeed, for TUT users, battery life seems to be significantly more important than for UPB users, a finding that could be explained by the fact that TUT users are all exchange students with likely more history of travelling than UPB users and which are likely to use their mobile device more (both for navigation and communication), and therefore might have experienced the inconveniences of a short battery life more often. Regarding user-given input, TUT students are significantly more reluctant than UPB students to give any feedback regarding their accuracy, even if a bonus from the operator is received. This difference is hard to explain and might come from the non-homogeneity of TUT group, compared with UPB group.

\section{Design Recommendations}

This section aims at suggesting some important design constraints and possible location-based services to meet users' preferences and needs, according to the survey's results.

An example of the interactions between user cognitive domain, contextual information and designer domain is illustrated in Figure 20. The user cognitive domain refers first and foremost to the user-defined profile and LBS-related activity in view, such as locating, searching, navigating, tracking lost items, etc. The contextual information such as mobility models and scenarios (indoor/outdoor, pedestrian/moderate speed/high speed, etc.) can be either user defined (coming from the user cognitive domain) or based on probabilistic approaches (coming from the designer domain) or a hybrid solution between the two (minimal user settings/input/feedback plus a probabilistic model with adaptive parameters based on users' settings).

Figure 20. Paradigm of future mobile devices with LBS.

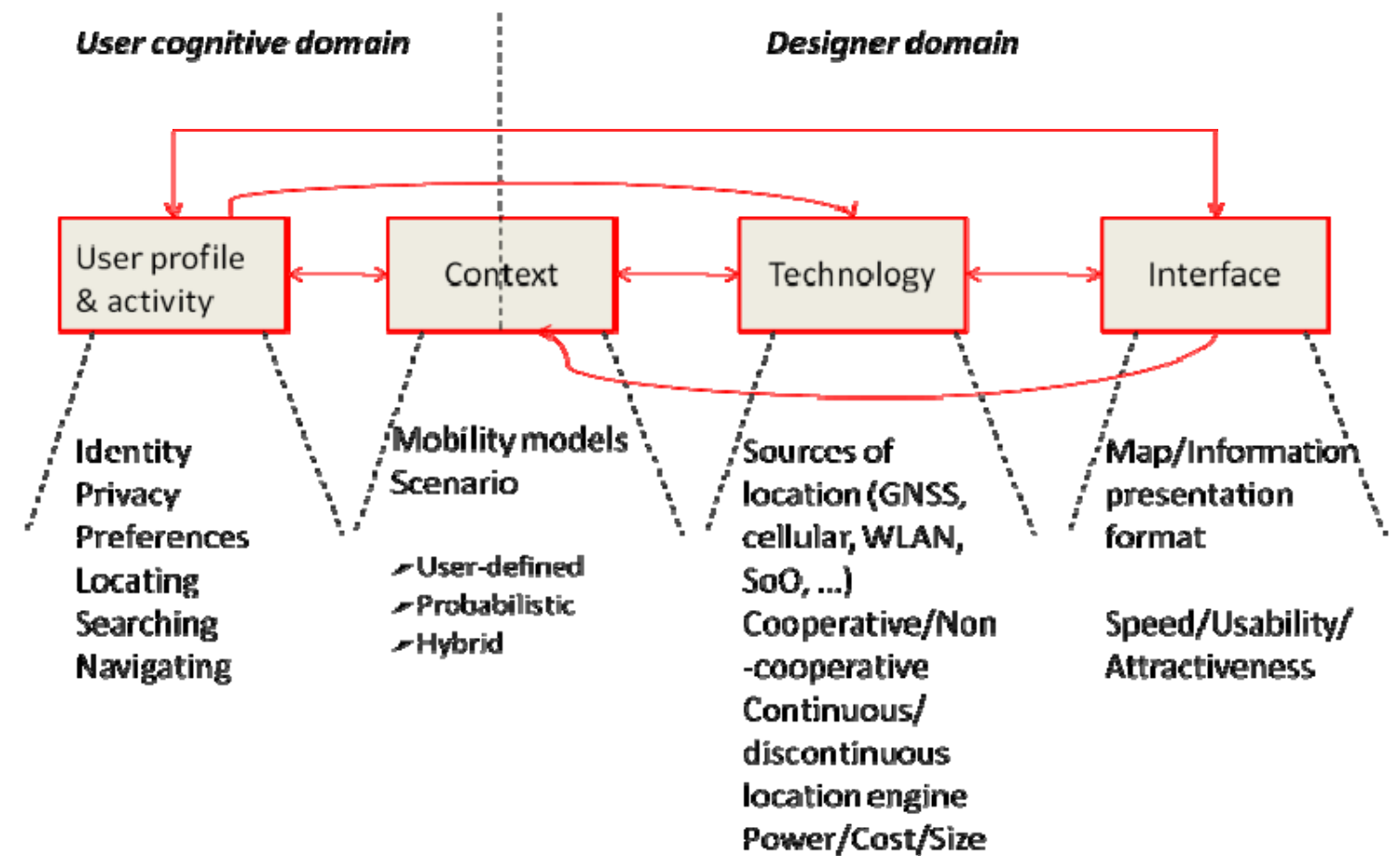


The technological constraints remain the known ones, such as cost, power, robustness, and size of the mobile device, to which features related to high availability and moderate accuracy of the navigation unit should be incorporated.

In terms of LBS interface, the general opinion of the interviewed students is that speed of the application or a quick processing time is most important, followed by the simplicity of use and a reasonable amount of user-defined settings. User-defined settings are in fact preferable in terms of overcoming or diminishing users' privacy concerns. The attractiveness of the interface is a 'nice-to-have' feature, something that may differentiate between otherwise similar mobile device designs, but not something that users are willing to pay much extra for.

We can see that the LBS-enabled mobile device architecture is a two-way architecture: the designer domain may influence the user cognitive domain, and the user cognitive domain will influence the designer domain. The context influences both domains and tailored-specific applications and algorithms may be envisaged, dividing, for example, the context into scenarios (indoor/outdoor, stationary/moderate speed/high speed, etc.). Many spatial systems are by nature "all-encompassing", and thus it may not be easy for the user to convey their goals. If a user has to specifically provide information that the system could have worked out on the basis of available contextual information, it could degrade the usability 11 . However, as our survey results showed, a reasonable amount of user-defined settings is seen favorably by most users. Moreover, cooperative positioning looks like an attractive option to the end-user, since it promises to fulfill both his/her desire for better accuracy and availability and his/her wish of doing something beneficial for the peers. Indeed, the study group confessed a high interest in applications concerning an increased social wellbeing.

From the end-user perspective, the main focus in the design of future LBS turns out to be on robustness and battery life. This calls for an effective design at both hardware and software level. Additionally, software engineering and new algorithm development are needed to enhance the navigation performance, which appear as important criteria in the choice of a location-enabled mobile device.

\section{Conclusions}

Recent years have seen a strong increase of wireless positioning technologies into our daily lives. In the particular field of Location-Based Services and their future evolution, there are a few key points to consider, such as: hardware constraints, privacy constraints, and the ratio between costs of end-user device and monthly subscription and LBS attractiveness. It can be considered that the novelty of our descriptive research is given by the fact that we conducted the study in two European countries which present relatively different social and economic environments. One limitation of our research is that the subjects of our survey represent an age/profession group that does not fully characterize the whole population of the country. Further research should consider a cross-sectional study. Also, user behavior is dynamic, so a longitudinal research (i.e., tracking the preferences of the same people over time) may provide more insights on user behavior development.

Based on our survey results, it appears that several incentives (to come from the service provider side) towards a larger adoption of paid LBS applications in the future are possible:

- Presenting the LBS applications in terms of increased social wellbeing, by clearly pointing out how such an application would be beneficial for society at large. Increased social wellbeing, 
decreased pollution and more environmentally friendly driving are very attractive features from the end-user point of view and more important than some features related strictly to some individual gain, such as the fanciness of the device or the infotainment/entertainment value.

- Motivating users to become interactive in the LBS-related settings (such as privacy, mobility or scenario settings and user location accuracy feedback)-this motivation can come, for example, in the form of a certain bonus activated in the LBS package as soon as a certain interactivity threshold is reached.

- Offering more attractive and more reliable safety-related LBS applications, such as help and accurate location in emergency cases, forecast and announcements of natural disasters or even local accidents/perturbations, etc.

It also appears that, in the future, being able to offer an increased social value in terms of the wellbeing of the user and their peers will have a significant impact on whether or not the user will accept and continue to use location technology and services that are not offered for free.

The other main findings of our surveys are summarized below:

- The majority of the surveyed students are happy with a moderate accuracy of few tens of meters; a very high accuracy is not so important for them as a very high availability of the position location.

- The most attractive applications from the end-user point of view are those that will 'ease' their life and their peers' life, rather than those that would offer a 'nice-to-have' feature. For example, being able to receive and offer help in emergency situations or getting health advices based on own mobility patterns are more important than social networking, geo-tagging or LBS-enabled advertising.

- The most important scenarios from the surveyed students' point of view, where they would like to have their location coordinates available with high accuracy, are outdoors and at low to moderate speeds. Other scenarios are also important, but not necessarily with a very high accuracy.

- If a designer has to choose which features of the mobile device to compromise in order to achieve better location accuracy, we saw that the users are more willing to accept an extra size or extra weight of their mobile device than to accept a shorted battery life or a decreased processing time/speed of the application.

- Personalized and increased accuracy emergency location-based services (e.g., getting information about friends/family in need) have a great potential to attract consumer revenues in the future.

- Local search and navigation services are likely to continue to be, by far, the largest revenue LBS applications.

\section{Acknowledgments}

This work was supported by the Nokia Foundation Visiting Professor Grant and by the Academy of Finland, which are gratefully acknowledged. This work was also supported partly by the Sectoral Operational Programme Human Resources Development 2007-2013 of the Romanian Ministry of Labour, Family and Social Protection through the Financial Agreement POSDRU/88/1.5/S/61178 and by the grant PN II Parteneriate 92-100/2008, 2008-2011. 


\section{References and Notes}

1. Xu, H.; Teo, H.H.; Tan, B.C.; Agarwal, R. The Role of Push-Pull Technology in Privacy Calculus: The Case of Location-Based Services. J. Manage. Inf. Syst. 2010, 26, 135-173.

2. Vrček, N.; Bubaš, G.; Bosilj, N. User Acceptance of Location-based Services. Int. J. Hum. Soc. Sci. 2009, 4, 152-157.

3. Chang, S.E.; Hsieh, Y.J.; Lee, T.R.; Lia, C.K.; Wang, S.T. A User Study on the Adoption of Location Based Services. APWeb/WAIM Ws, LNCS 4537, 2007; Springer-Verlag: Heidelberg, Germany, 2007; pp. 276-286.

4. ABI Press release. Availiable at http://www.gpsworld.com/lbs/news/abi-research-lbs-subscribersincrease-18-million-6955 (accessed on 2 July 2011).

5. "Location-Based Services (LBS) Markets: Carrier vs. Application Store", ABI research market study, 4Q 2010.

6. Kim, D. Automotive Research Portal-Portable devices and LBS, research portal at iSuppli Market Intelligence, 2010.

7. Raper, J. Design constraints on operational LBS. Location Based Services and Telecartography, Series: Lecture Notes in Geoinformation and Cartography; Gartner, G., Cartwright, W., Peterson, M.P., Eds.; Springer: Heidelberg, Germany, 2007; pp. 13-25.

8. Morrison, D.A. Young Adults, Emerging Technology, and Investing: The New Way of Doing Business, Trends in research note (active Jun 2011), Availiable at http://www.twentysomething.com/mraalert.htm (accessed on 30 June 2011).

9. Gerpott, T.J.; Berg, S. Adoption of location-based service offers of mobile network operators-An empirical study of German consumers. In Proceedings of IEEE Ninth International Conference on Mobile Business (ICMB-GMR), Athens, Greece, June 2010; pp. 154-160.

10. Androulidakis, I.; Papapetros, D. Survey findings towards awareness of mobile phones' security issues, recent advances in data networks, communications, computers. In Proceedings of 7th WSEAS International Conference on Data Networks, Communications, Computers (DNCOCO '08), November 2008; pp. 130-135.

11. Uhlirz, M. A Market and User View on LBS. Location Based Services and Telecartography, Series: Lecture Notes in Geoinformation and Cartography, Gartner, G., Cartwright, W., Peterson, M.P., Eds.; Springer: Berlin, Germany, 2007; pp. 47-58.

12. Bilton, N. Facebook Will Allow Users to Share Location; The New York Times: New York, NY, USA, 2010.

13. Tsai, J.Y.; Kelley, P.; Drielsma, P.; Cranor, L.F.; Hong, J.; Sadeh, N. Who's viewed you? The impact of feedback in a mobile-location system. In Proceedings of the 27th annual SIGCHI Conference on Human Factors in Computing Systems, Boston, MA, USA, April 2009; pp. 2003-2012.

14. Delfos, J.; Tan, T.; Veenendaal, B. Design of a Web-Based LBS Framework Addressing Usability, Cost, and Implementation Constraints. World Wide Web 2010, 13, 391-418.

15. Kanji, G.K. 100 Statistical Tests; SAGE publications: New York, NY, USA, 2006; pp. 21-101.

16. Cardillo, G. NSCORES: Van der Waerden normal scores version of several non-parametric tests, 2010. Available at http://www.mathworks.com/matlabcentral/fileexchange/26855 (accessed on 29 June 2011). 
17. Trujillo-Ortiz, A.; Trujillo-Rodriguez, F.A.; Hernandez-Walls, R.; Fligner, M.A.; Perez-Osuna, S. FPtest: Non-parametric Fligner-Policello test of two combined random variables with continuous cumulative distribution, 2003. Availiable at http://www.mathworks.com/matlabcentral/fileexchange/ loadFile.do?objectId=4226\&objectType=FILE (accessed on 29 June 2011).

18. Fligner, M.A.; Policello, G.E. Robust rank procedure for the Behrens-Fisher Problem. J. Am. Stat. Assoc. 1981, 76, 162-168.

19. Hollander, M.; Wolfe, D.A. Nonparametric Statistical Methods, 2nd ed.; John Wiley and Sons: New York, NY, USA, 1999; pp. 135-139.

(C) 2011 by the authors; licensee MDPI, Basel, Switzerland. This article is an open access article distributed under the terms and conditions of the Creative Commons Attribution license (http://creativecommons.org/licenses/by/3.0/). 